\title{
Childhood malnutrition is associated with maternal care during pregnancy and childbirth: a cross-sectional study in Bauchi and Cross River States, Nigeria
}

\author{
Candyce Hamel, ${ }^{1}$ Joseph Enne, ${ }^{2}$ Khalid Omer, ${ }^{2}$ Ndem Ayara, ${ }^{3}$ Yahaya Yarima, ${ }^{4}$ \\ Anne Cockcroft, ${ }^{5}$ Neil Andersson ${ }^{1}$ \\ 'CIET-PRAM, Department of Family Medicine, McGill University, Montreal, Canada; ${ }^{2}$ CIET \\ Trust, Johannesburg, South Africa; ${ }^{3}$ State Planning Commission, Cross River State \\ Government, Calabar, Nigeria; ${ }^{4}$ Bauchi State Primary Health Care Development Agency, \\ Bauchi, Nigeria; ${ }^{5} \mathrm{CIET}$ Trust, Gaborone, Botswana
}

\begin{abstract}
Significance for public health
Childhood malnutrition is a public health priority, accounting for almost 1/5 of global disease burden among children under five years old. Many studies have examined risk factors for childhood malnutrition, but few have examined the link between maternal care during pregnancy and childbirth and childhood malnutrition. This study, albeit a cross-sectional design, provides evidence of a link between poor care during pregnancy and childbirth and childhood malnutrition in two states of Nigeria. This is important for public health because it suggests another benefit of caring for women during pregnancy and childbirth. This could not only reduce maternal and child perinatal mortality, but also have benefits for the longer-term health and development of children. This finding could be useful for paternal advocacy; it may motivate men to support their wives during pregnancy and childbirth since through this support, fathers can also protect the future development of their children.
\end{abstract}

\footnotetext{
Abstract

Background. Malnutrition remains an important cause of childhood morbidity and mortality; the levels of childhood malnutrition in Nigeria are among the highest in the world. The literature supports many direct and indirect causes of malnutrition, but few studies have examined the link between maternal care during pregnancy and childbirth and childhood malnutrition. This study examines this potential link in Bauchi and Cross River states in Nigeria.

Design and methods. In 2011, a household survey collected information about children under four years old and their mothers' last pregnancy. Trained fieldworkers measured mid-upper arm circumference (MUAC) of children aged 6-47 months. We examined associations with childhood malnutrition in bivariate and multivariate analysis.

Results. Some $4.4 \%$ of 3643 children in Cross River, and 14.7\% of 2706 in Bauchi were malnourished (MUAC z-score). In both states, a child whose mother had fewer than four government antenatal care visits was more likely to be malnourished (Cross River: OR 1.85, $95 \% \mathrm{CI}_{\text {са }} 1.33-2.55$; Bauchi: OR 1.29, 95\% $\left.\mathrm{CI}_{\text {са }} 1.02-1.63\right)$. In Bauchi, a child whose mother who rarely or never discussed pregnancy and childbirth with her husband (OR 1.34, 95\% $\mathrm{CI}_{\mathrm{ca}}$ 1.07-1.68), and who did not have her last delivery attended by a skilled health worker was
}

more likely to be malnourished (OR $\left.1.50,95 \% \mathrm{CI}_{\text {ca }} 1.09-2.07\right)$.

Conclusions. These findings, if confirmed in other studies, suggest that poor care of women in pregnancy and childbirth could pose a longer term risk to the health of the child, as well as increasing immediate risks for both mother and child.

\section{Background}

Childhood malnutrition accounts for almost one-fifth of global disease burden among children under five years old. ${ }^{1}$ In 2005 , stunting, severe wasting, and intrauterine growth restriction together were estimated to be responsible for 2.2 million deaths and $21 \%$ of loss of disability-adjusted life-years in children under five years old. ${ }^{2}$ Reduction in malnutrition relates to two of the World Health Organizations (WHO) Millennium Development Goals (MDGs): MDG 1 is aimed at eradicating extreme hunger and poverty, ${ }^{3}$ and MDG 4 is aimed at reducing child mortality. ${ }^{4}$ The percentage of underweight and stunted children worldwide has declined since the $1990 \mathrm{~s}^{3}$ However, some 99 million children under five years old were estimated to be underweight in 2013 and, in Africa, the number of stunted children increased from 46 million in 1990 to 59 million in $2013 .{ }^{3}$ It is estimated that 195 million children under five years old in developing countries suffer from stunting, more than $90 \%$ of them in Asia and Africa. ${ }^{5}$

The 2011 Multiple Indicator Cluster Survey in Nigeria reported that $24 \%$ of children under five years old were moderately underweight, $9 \%$ were severely underweight, and $55 \%$ were moderately or severely stunted. ${ }^{6}$ These are among the highest rates of malnutrition in Sub-Saharan Africa.

UNICEF describes the complex causes of malnutrition under two main categories, immediate and underlying causes. Immediate causes of malnutrition are inadequate dietary intake and illness. The underlying causes that lead to inadequate dietary intake and infectious disease include inadequate household access to food, poor health services, unhealthy environments, and inadequate care of children and women. ${ }^{7}$ Few studies have described dietary, demographic, socioeconomic, and environmental factors linked to childhood malnutrition. ${ }^{8-13}$

There is little reported research examining the possible link between the care a woman receives during pregnancy and childbirth and childhood malnutrition. A study in southern Ethiopia found that 
the number of antenatal visits a mother had during pregnancy was inversely related to stunting in the child. ${ }^{14}$ A report from the WHO, noted that good antenatal care links the woman and her family with the formal health system, increases the chance of using a skilled attendant at birth and contributes to good health through the life cycle. ${ }^{15}$ Antenatal visits are an indicator of contact with health services and health seeking behaviour, which may be associated with better care and feeding practices for young children. The pathways through which antenatal care may itself promote child nutrition need further exploration. Possible mechanisms include giving mothers information about childhood feeding practices, including exclusive breastfeeding, giving information about prevention of childhood illnesses, and preparing and supporting mothers generally for care of newborn children.

The study described here used data collected in a household survey in Bauchi and Cross River States in Nigeria to examine the association, if any, between care of women during pregnancy and childbirth and nutritional status of their young children.

\section{Design and methods}

From July to September 2011, trained field teams carried out a household survey about prevention and treatment of childhood illnesses in Bauchi and Cross River States of Nigeria. The survey was part of a programme to support evidence-based planning of health services. ${ }^{16,17}$ The stratified random cluster sample of 90 sites in each state, based on enumeration areas of the 2006 census, included sites in each Local Government Authority (LGA). The urban/rural balance in the sample was proportionate to the urban/rural distribution of the population in each state. The cluster in each community comprised contiguous households radiating from a random starting point and continuing until about 100 children were covered. There was no subsampling within the cluster.

The population of Bauchi State, in the north of Nigeria, is predominantly Muslim and the main ethnic group is Hausa. In Cross River state, in the south east of the country, the three major ethnic groups are the Efik, Ejagham, and Bekwarra, and Christianity is the main religion. Levels of education and literacy are higher in Cross River than in Bauchi. ${ }^{18,19}$

During the survey, trained interviewers administered a questionnaire to women of childbearing age (15-49 years). The questionnaire asked about socio-economic status, about care and experiences during the last pregnancy, about experience of domestic violence, and about the health and care of each child under four years old. In order to assess nutritional status, trained operators measured mid-upper arm circumference (MUAC), to the nearest millimetre, of children aged 6-47 months old using the TALC tape.$^{20}$ Authors have debated the role of MUAC as an accurate means of assessing malnutrition. A study in a Rwandan refugee camp found an unsatisfactory balance of sensitivity and specificity for MUAC, using weight-for-height as the gold standard. ${ }^{21}$ Other authors quickly responded that the role of MUAC is not to estimate weight-for-height and that MUAC is a better predictor than weight-for-height of mortality and clinical kwashiorkor. $^{22,23}$ MUAC is a robust and reliable method of estimating childhood malnutrition, ${ }^{24}$ especially in field surveys when obtaining accurate height and weight measurements is difficult.

\section{Analysis}

Trained operators entered the data using EPI Info version $6{ }^{25}$ Double-data entry with validation minimised key-stroke errors and further cleaning checked for logical errors. Analysis relied on CIETmap software, which provides a user-friendly interface with the
R statistical language. ${ }^{26}$ We calculated z-scores from MUAC measurements using Anthro to take into account age and sex of the child. ${ }^{27}$ We classified children as malnourished if they fell below two standard deviations (SD) of the median age and sex adjusted z-score.

The unit of analysis was a child aged 6-47 months. We included a child in the analysis if the mother was the respondent, the child was from the mother's last live pregnancy, the child was between the ages of six and 47 months (inclusive), and the child had complete data to calculate a MUAC z-score (date of birth, sex and MUAC measurement). We weighted all estimates proportional to the population in each state, including rural and urban characteristics, and allowing for the over-sampling in the three focus LGAs in each state.

We analysed the two states separately. There is no intention to assess that the two states represent the whole country, and we discussed the state-specific findings with the health authorities in the two states, as part of a programme to support evidence-based planning at state level. ${ }^{16,17}$

We examined the effects of a number of potential determinants on malnutrition among children aged 6 to 47 months old, in bivariate and then multivariate analysis. Multivariate analysis used the MantelHaenszel procedure, ${ }^{28}$ adjusted for clustering at community level..$^{29}$ Initial saturated models included all factors significantly associated with malnutrition in bivariate analysis, as well as any variables considered likely to be associated with malnutrition based on previous evidence, even if not significantly associated with malnutrition at the $5 \%$ level. The analysis removed variables from the model one at a time, each time removing the variable with the lowest cluster adjusted Mantel-Haenszel summary chi-square value, until all remaining variables were significantly associated with the outcome. We tested for interaction between variables in the models using Zelen's test for interaction. We describe associations using the adjusted Odds Ratio $(\mathrm{OR})$ and cluster-adjusted $95 \%$ confidence intervals $\left(\mathrm{CI}_{\mathrm{ca}}\right)$.

The potential determinants of childhood malnutrition examined included maternal care during pregnancy and childbirth, other maternal characteristics, child characteristics, and household and community characteristics. Maternal care during pregnancy and childbirth: Whether the mother reduced her heavy work by the third trimester, received four government ante-natal care (ANC) visits, experienced physical abuse from her partner/husband during her last pregnancy, had her last delivery attended by a skilled worker, and had a post-natal check-up (PNC) within six weeks of her last delivery. Maternal characteristics: Marital status, level of education [(more education was more than junior secondary in Cross River and any formal education in Bauchi (since few mothers in Bauchi had any formal education)], any maternal income, the number of children cared for (higher risk defined as three or more children), food security (not enough food in the last week was an indicator of serious poverty), and ability to speak to the husband or partner about pregnancy and childbirth. Child characteristics: Sex, age (under 24 months or 25-47 months), whether given colostrum after birth, whether exclusively breastfed (no other liquids or solids) for six months, whether experienced diarrhoea in the last two weeks, and whether experienced acute respiratory illness (ARI) two or more times in the last year. Household and community characteristics: Rural or urban dwelling, level of household crowding (crowded defined as two or more individuals per room), self-perceived relative household financial situation, and whether a government health facility was present in the community.

\section{Results}

Field teams visited 10,230 households in Cross River and 5571 households in Bauchi and interviewed three-quarters of the house- 
holds in Cross River (75\%, 7685/10230) and almost every household in Bauchi $(99 \%, 5535 / 5571)$. From these households, they collected information on 11,305 children in Cross River and 11,284 children in Bauchi. In Cross River state, the mother of the child responded for 9827 children, 8429 children were between the ages of 6 and 47 months, 7551 children had complete information to calculate a MUAC z-score, and 3643 children were from the mother's last pregnancy and were included in the analysis. In Bauchi state, the mother of the child responded for 10,812 children, 8825 children were between the ages of 6 and 47 months, 6837 children had complete information to calculate a MUAC z-score, and 2706 children were from the mother's last pregnancy and were included in the analysis.

Some 4.4\% (160/3643) of the children in Cross River, and 14.7\% (398/2706) of the children in Bauchi were classified as malnourished, based on a MUAC z-score more than 2 SD below the median. Table 1 shows the frequency of the maternal, child, and household/community characteristics potentially related to childhood malnutrition. In Bauchi, most women $(87 \%, 2340 / 2692)$ did not reduce heavy work by the third trimester, over half of the women had fewer than four government ANC visits, and four out of every five women did not have a skilled health worker at her last delivery and did not receive a PNC visit within six weeks of delivery. One in ten of the women in Bauchi reported physical abuse during pregnancy. In Cross River, nearly seven out of every ten women did not reduce their heavy workload by the third trimester, approximately four in ten women did not receive at least four government ANC visits and did not have their delivery attended by a skilled health worker, and three out of four women did not receive a PNC visit within six weeks of delivery. A quarter reported physical abuse during pregnancy.

Table 2 lists the results of bivariate analysis of associations between individual determinants and child nutritional status for each state. In both states, a child whose mother did not receive four or more government ANC visits, did not have a skilled health worker at her last delivery, and rarely or never discussed issues related to pregnancy and childbirth with her husband or partner was more likely to malnourished. Female children and children who had ARI two or more times in the last year were more likely to be malnourished.

Table 3 shows the final multivariate models of factors related to childhood malnutrition for each state. Care of the mother during her last pregnancy remained significantly associated with child malnutrition. In both states, a child whose mother had fewer than four government ANC visits during her last pregnancy was more likely to be malnourished. In Bauchi, a child whose mother rarely or never discussed issues related to pregnancy and childbirth with her husband or partner and a child whose mother did not have her last delivery attended by a skilled health worker was more likely to be malnourished. One other maternal factor was associated with malnutrition in Cross River, where a child whose mother had less than junior secondary education was more likely to be malnourished.

Care of the child and childhood illnesses were related to malnutrition in Bauchi. Having diarrhoea in the last two weeks and ARI two or more times in the last year were associated with child malnutrition. In both states, female children were more likely to be malnourished than male children.

\section{Discussion}

The rates of malnutrition among children aged 6-47 months in our study, assessed by age- and sex-adjusted MUAC z-scores, were $4.4 \%$ in Cross River and 14.7\% in Bauchi. These figures, indicating more

Table 1. Potential determinants of childhood malnutrition (children aged 6 to 47 months from mother's last pregnancy, with a MUAC score).

\begin{tabular}{|c|c|c|}
\hline Information & Bauchi, \% & Cross River, \% \\
\hline $\begin{array}{l}\text { A child whose mother... } \\
\text { is not married } \\
\text { has no formal education/less than junior secondary education }{ }^{\text {a }} \\
\text { does not have her own income } \\
\text { has } 3 \text { or more children } \\
\text { has no food security } \\
\text { is not able to speak to husband about pregnancy and childbirth }\end{array}$ & $\begin{array}{c}1(36 / 2701) \\
78(2103 / 2706) \\
35(939 / 2703) \\
61(1656 / 2701) \\
10(253 / 2705) \\
45(1121 / 2677)\end{array}$ & $\begin{array}{l}11(385 / 3630) \\
36(1338 / 3627) \\
42(1547 / 3639) \\
49(1801 / 3640) \\
18(679 / 3640) \\
34(1237 / 3614)\end{array}$ \\
\hline $\begin{array}{l}\text { Maternal care during her last pregnancy } \\
\text { Did not reduce heavy work by 3rd trimester } \\
\text { Less than } 4 \text { government ante-natal visits } \\
\text { Experienced abuse during pregnancy } \\
\text { Did not have a skilled health worker at delivery } \\
\text { Did not have post-natal check-up within } 6 \text { weeks of delivery }\end{array}$ & $\begin{array}{c}88(2340 / 2692) \\
51(1379 / 2700) \\
9(236 / 2371) \\
80(2139 / 2685) \\
79(2024 / 2585)\end{array}$ & $\begin{array}{l}68(2403 / 3568) \\
44(1558 / 3610) \\
25(810 / 3226) \\
42(1529 / 3605) \\
75(2490 / 3328)\end{array}$ \\
\hline $\begin{array}{l}\text { Child information } \\
\text { Female child } \\
\text { Child under two years old } \\
\text { Not given colostrum } \\
\text { Not exclusively breastfed for exactly six months } \\
\text { Had diarrhoea in the past two weeks } \\
\text { Two or more ARI episodes in the past year }\end{array}$ & $\begin{array}{l}49(1332 / 2706) \\
76(2042 / 2706) \\
23(646 / 2698) \\
91(2466 / 2706) \\
42(1146 / 2659) \\
66(1761 / 2650)\end{array}$ & $\begin{array}{l}49(1812 / 3642) \\
76(2716 / 3643) \\
12(455 / 3620) \\
81(2966 / 3643) \\
10(371 / 3549) \\
19(703 / 3585)\end{array}$ \\
\hline $\begin{array}{l}\text { Household and community information } \\
\text { Lives in a rural area } \\
\text { Lives in a crowded house } \\
\text { Perceived household financial situation is less than average } \\
\text { Community does not have a government health facility }\end{array}$ & $\begin{array}{c}78(2193 / 2706) \\
69(1887 / 2685) \\
17(469 / 2691) \\
40(993 / 2696)\end{array}$ & $\begin{array}{c}67(2437 / 3643) \\
69(2469 / 3620) \\
34(1258 / 3624) \\
24(798 / 3541)\end{array}$ \\
\hline
\end{tabular}

aWe used no formal education in Bauchi and less than junior in Cross River; bRespondents' with inadequate privacy or language difficulties were not asked questions regarding domestic violence. 
Table 2. Childhood malnutrition status by potential risk factors related to care during pregnancy and childbirth (children aged 6 to 47 months from mother's last pregnancy, with a MUAC score).

\begin{tabular}{|c|c|c|c|c|}
\hline \multirow[t]{2}{*}{ Characteristic } & \multicolumn{2}{|c|}{ Bauchi } & \multicolumn{2}{|c|}{ Cross River } \\
\hline & $\%$ malnourished & OR $\left(95 \% \mathrm{CI}_{\mathrm{ca}}\right)$ & $\%$ malnourished & OR $\left(95 \% \mathrm{CI}_{\mathrm{ca}}\right)$ \\
\hline \multicolumn{5}{|c|}{ Care during last pregnancy } \\
\hline $\begin{array}{l}\text { Reducing heavy work by 3rd trimester } \\
\text { Yes } \\
\text { No }\end{array}$ & $\begin{array}{c}12.5(44 / 352) \\
15.0(352 / 2340)\end{array}$ & $1.24(0.89-1.73)$ & $\begin{array}{c}3.3(38 / 1165) \\
4.9(118 / 2403)\end{array}$ & $1.53(1.06-2.22)$ \\
\hline $\begin{array}{l}\text { Number of government ANC visits } \\
4 \text { or more } \\
\text { Less than } 4\end{array}$ & $\begin{array}{l}12.2(161 / 1321) \\
17.2(237 / 1379)\end{array}$ & $1.50(1.18-1.90)$ & $\begin{array}{l}3.1(63 / 2052) \\
6.1(95 / 1558)\end{array}$ & $2.05(1.52-2.76)$ \\
\hline $\begin{array}{l}\text { Abuse during pregnancy } \\
\text { No } \\
\text { Yes }\end{array}$ & $\begin{array}{c}14.8(316 / 2135) \\
13.6(32 / 236)\end{array}$ & $0.90(0.61-1.34)$ & $\begin{array}{l}3.8(92 / 2416) \\
5.3(43 / 810)\end{array}$ & $1.42(0.97-2.07)$ \\
\hline $\begin{array}{l}\text { Skilled health worker at delivery } \\
\text { Yes } \\
\text { No }\end{array}$ & $\begin{array}{c}9.7(53 / 546) \\
16.0(342 / 2139)\end{array}$ & $1.77(1.28-2.46)$ & $\begin{array}{l}3.6(74 / 2076) \\
5.4(83 / 1529)\end{array}$ & $1.55(1.02-2.36)$ \\
\hline $\begin{array}{l}\text { PNC visit within } 6 \text { weeks of delivery } \\
\text { Yes } \\
\text { No }\end{array}$ & $\begin{array}{c}11.8(66 / 560) \\
15.7(318 / 2024)\end{array}$ & $1.40(1.03-1.89)$ & $\begin{array}{c}3.6(30 / 838) \\
4.5(113 / 2490)\end{array}$ & $1.28(0.82-2.00)$ \\
\hline \multicolumn{5}{|c|}{ Maternal information } \\
\hline $\begin{array}{l}\text { Mother's marital status } \\
\text { Married/co-habitating } \\
\text { Single/widowed/divorced/separated }\end{array}$ & $\begin{array}{c}14.8(394 / 2665) \\
11.1(4 / 36)\end{array}$ & $0.72(0.25-2.09)$ & $\begin{array}{c}4.3(138 / 3245) \\
5.5(21 / 385)\end{array}$ & $1.30(0.76-2.22)$ \\
\hline $\begin{array}{l}\text { Mother's education } \\
\text { Some formal educ/junior or higher } \\
\text { No formal educ/less than junior }\end{array}$ & $\begin{array}{c}10.3(62 / 603) \\
16.0(336 / 2103)\end{array}$ & $1.66(1.11-2.48)$ & $\begin{array}{l}3.2(74 / 2289) \\
6.4(85 / 1338)\end{array}$ & $2.03(1.47-2.81)$ \\
\hline $\begin{array}{l}\text { Mother has own income } \\
\text { Yes } \\
\text { No }\end{array}$ & $\begin{array}{l}13.8(243 / 1764) \\
16.5(155 / 939)\end{array}$ & $1.24(1.00-1.53)$ & $\begin{array}{l}4.1(86 / 2092) \\
4.8(74 / 1547)\end{array}$ & $1.17(0.86-1.59)$ \\
\hline $\begin{array}{l}\text { Mother's food security in last week } \\
\text { Had food security } \\
\text { No food security }\end{array}$ & $\begin{array}{l}14.4(354 / 2452) \\
17.0(43 / 253)\end{array}$ & $1.21(0.87-1.69)$ & $\begin{array}{c}4.3(126 / 2961) \\
5.0(34 / 679)\end{array}$ & $1.19(0.82-1.72)$ \\
\hline $\begin{array}{l}\text { Number of children } \\
0-2 \text { children } \\
3 \text { or more children }\end{array}$ & $\begin{array}{l}15.3(160 / 1045) \\
14.3(237 / 1656)\end{array}$ & $0.92(0.73-1.17)$ & $\begin{array}{l}3.4(62 / 1839) \\
5.4(98 / 1801)\end{array}$ & $1.65(1.17-2.32)$ \\
\hline $\begin{array}{l}\text { Speak to husband about pregnancy and ch } \\
\text { Yes } \\
\text { No }\end{array}$ & $\begin{array}{l}\text { irth } \\
12.9(201 / 1556) \\
17.3(194 / 1121) \\
\end{array}$ & $1.41(1.15-1.74)$ & $\begin{array}{l}3.8(90 / 2377) \\
5.6(69 / 1237)\end{array}$ & $1.50(1.05-2.14)$ \\
\hline \multicolumn{5}{|c|}{ Child information } \\
\hline $\begin{array}{l}\text { Sex of child } \\
\text { Male } \\
\text { Female }\end{array}$ & $\begin{array}{l}12.2(167 / 1374) \\
17.3(231 / 1332)\end{array}$ & $1.52(1.25-1.85)$ & $\begin{array}{l}3.4(63 / 1830) \\
5.3(96 / 1812)\end{array}$ & $1.57(1.13-2.18)$ \\
\hline $\begin{array}{l}\text { Given colostrum } \\
\text { Yes } \\
\text { No }\end{array}$ & $\begin{array}{l}13.8(283 / 2052) \\
17.6(114 / 646)\end{array}$ & $1.34(1.07-1.67)$ & $\begin{array}{c}4.2(133 / 3165) \\
5.9(27 / 455)\end{array}$ & $1.44(0.98-2.11)$ \\
\hline $\begin{array}{l}\text { Exclusively breastfed for } 6 \text { months } \\
\text { Yes } \\
\text { No }\end{array}$ & $\begin{array}{c}12.9(31 / 240) \\
14.9(367 / 2466)\end{array}$ & $1.18(0.78-1.78)$ & $\begin{array}{c}3.0(20 / 677) \\
4.7(140 / 2966)\end{array}$ & $1.63(1.05-2.51)$ \\
\hline $\begin{array}{l}\text { Diarrhoea in the past two weeks } \\
\text { No } \\
\text { Yes }\end{array}$ & $\begin{array}{l}12.0(181 / 1513) \\
18.3(210 / 1446)\end{array}$ & $1.65(1.37-1.99)$ & $\begin{array}{l}4.2(133 / 3178) \\
6.5(24 / 371)\end{array}$ & $1.58(0.93-2.70)$ \\
\hline $\begin{array}{l}\text { ARI episodes in the past year } \\
\text { Fewer than two } \\
\text { Two or more }\end{array}$ & $\begin{array}{l}11.4(101 / 889) \\
16.5(291 / 1761)\end{array}$ & $1.54(1.16-2.05)$ & $\begin{array}{l}4.0(115 / 2882) \\
6.0(42 / 703)\end{array}$ & $1.53(1.02-2.28)$ \\
\hline \multicolumn{5}{|c|}{ Household and community information } \\
\hline $\begin{array}{l}\text { Area } \\
\quad \text { Urban } \\
\text { Rural }\end{array}$ & $\begin{array}{c}10.5(54 / 513) \\
15.7(344 / 2193)\end{array}$ & $1.58(1.05-2.38)$ & $\begin{array}{l}4.6(56 / 1206) \\
4.3(104 / 2437)\end{array}$ & $0.92(0.58-1.44)$ \\
\hline $\begin{array}{l}\text { Perceived household financial situation } \\
\text { Average or above } \\
\text { Less than average }\end{array}$ & $\begin{array}{c}14.1(313 / 2222) \\
17.5(82 / 469)\end{array}$ & $1.29(0.96-1.73)$ & $\begin{array}{c}4.3(102 / 2366) \\
4.6(58 / 1258)\end{array}$ & $1.07(0.78-1.47)$ \\
\hline $\begin{array}{l}\text { Community access to a government HF } \\
\text { Yes } \\
\text { No }\end{array}$ & $\begin{array}{l}12.9(220 / 1703) \\
17.8(177 / 993)\end{array}$ & $1.46(1.05-2.03)$ & $\begin{array}{l}4.2(116 / 2743) \\
4.6(37 / 798) \\
\end{array}$ & $1.10(0.61-1.98)$ \\
\hline
\end{tabular}

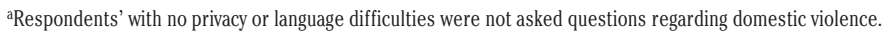


Table 3. Final multivariate models showing risk factors association with childhood malnutrition.

\begin{tabular}{|c|c|c|}
\hline Risk factors & Weighted OR & $95 \% \mathrm{CI}_{\mathrm{ca}}$ \\
\hline \multicolumn{3}{|l|}{ Bauchi $(\mathrm{n}=2543)^{\mathrm{a}}$} \\
\hline Mother rarely or never discusses issues related to pregnancy and childbirth with husband or partner & 1.34 & $1.07-1.68$ \\
\hline Mother had fewer than four government ANC visits & 1.29 & $1.02-1.63$ \\
\hline No skilled health worker at delivery & 1.50 & $1.09-2.07$ \\
\hline Female child & 1.55 & $1.25-1.91$ \\
\hline Had diarrhoea in the last two weeks & 1.52 & $1.27-1.83$ \\
\hline Had ARI two or more times in the past year & 1.39 & $1.07-1.82$ \\
\hline \multicolumn{3}{|l|}{ Cross River $(\mathrm{n}=3593)^{\mathrm{b}}$} \\
\hline Mother had fewer than four government ANC visits & 1.85 & $1.33-2.55$ \\
\hline Mother had less than junior secondary education & 1.84 & $1.31-2.57$ \\
\hline Female child & 1.59 & $1.16-2.17$ \\
\hline
\end{tabular}

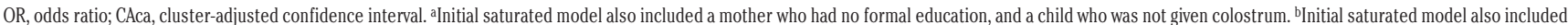
a child who was not exclusively breastfed for 6 months, a mother who did not reduce/never reduced her heavy workload by the third trimester, a mother who had 3 or more children to look after, and a mother who rarely or never discusses issues related to pregnancy and childbirth with husband/partner.

childhood malnutrition in Bauchi than in Cross River, are similar to figures from the 2011 MICS national survey, which reported $5.0 \%$ of children aged 0-59 months in Cross River and 9.1\% in Bauchi were moderately or severely wasted (low weight-for-height). ${ }^{6}$

Among the mothers in our study, the proportion who had at least four government antenatal care visits was somewhat lower in Bauchi (49\%) than in Cross River (56\%). The difference between the two states was more marked in the 2011 MICS, which reported the proportion having four or more ANC visits (from any source) in the last pregnancy, among women aged 15-49, as 29\% in Bauchi and $60 \%$ in Cross River. ${ }^{6}$ In the present study, a woman's care during pregnancy and childbirth was associated with the nutritional status of her child, taking into account the effects of other variables associated with nutritional status of the child. If a woman received at least four government ANC visits (both states), was able to discuss issues related to pregnancy and childbirth with her husband (in Bauchi), and had a skilled health worker present at delivery (in Bauchi), her child was less likely to be malnourished. Other authors have found a positive association between antenatal care ${ }^{9,14}$ and skilled delivery, ${ }^{30}$ and having a child who was not underweight or stunted. The number of ANC visits may be important, with repeated visits providing more opportunity to discuss issues such as breastfeeding. The WHO, based on results from a multi-country randomised-controlled trial and a systematic review, recommends four visits as the basic requirement for healthy women. ${ }^{15}$ We cannot be sure if it is the particular care that matters or whether going for ANC visits and having skilled birth attendance reflect better overall care and attention to the pregnant woman. ANC visits might have a direct beneficial effect because they provide relevant advice and guidance, for example about breastfeeding practices, and prevention and management of childhood illnesses. The association might be indirect. If a pregnant woman is generally well supported and cared for by her family, she might attend ANC visits, breastfed more effectively, and be better able to care for her children generally.

This evidence of a link between care of a pregnant woman and nutritional status of her young children could be helpful when advocating for better care of pregnant women by their husbands and families. Since poor care of pregnant women may lead to malnutrition in their children, the message is that men who care for their wives or partners are safeguarding the health of their children as well as that of the women. Video docudramas developed to share the findings of the survey with communities and service providers in the two states included scenes making the point that care for a pregnant woman was important for the health of her child. This approach aligns with the
Scaling Up Nutrition (SUN) movement, 1000 Days Partnership, which highlights the importance of care for the mother from the beginning of pregnancy until the child's second birthday. The movement advocates for ensuring proper micronutrients for mother and child, promoting good nutritional practices, and treating malnourished young children with therapeutic foods, noting that improving nutrition for these first 1000 days can have a lifelong impact. ${ }^{31}$

Our study confirms previously reported findings about the role of other factors in childhood malnutrition. In both Cross River and Bauchi, female children were more likely to be malnourished than male children. Studies in Bangladesh, South Africa, and Nigeria have found higher rates of malnutrition among female children.8,11,32 Malnutrition can make a person more vulnerable to infection, and infection also contributes to malnutrition. ${ }^{33}$ In Bauchi, a child with recent diarrhoea (an indicator of more frequent bouts of diarrhoea) was more likely to be malnourished. It is recognised that frequent diarrhoea in children can lead to malnutrition, while malnutrition aggravates the course of diarrhoea. ${ }^{34}$ Malnutrition is a risk factor for respiratory infections, ${ }^{35}$ while respiratory infections increase the demand for energy, adversely affecting nutritional status. ${ }^{36}$

In Cross River, mothers who had less than a junior level of education were significantly more like to have a malnourished child. This has also been reported from elsewhere. Makoka analysed data from Demographic and Health Surveys and reported that children in Malawi, Zimbabwe, and Tanzania were significantly less likely to be malnourished when their mothers were more educated. ${ }^{37}$

\section{Conclusions}

In this study, maternal care during pregnancy and childbirth was associated with nutritional status of young children in two states of Nigeria, taking into account the other factors related to nutritional status that we measured. This is evidence in favour of the suggestion that poor care of women in pregnancy and childbirth could pose a longer term risk to the health of the child, as well as increasing the more immediate risks for both mother and child. This would need to be confirmed by further studies in different settings.

\section{Limitations}

This was a cross-sectional study, so we can only report on associations and conclusions about causality must be tentative. 
Correspondence: Candyce Hamel, CIET-PRAM, Department of Family Medicine, McGill University, Chemin de la Côte-des-Neige, 3rd floor, Montreal, Quebec 5858, H3S 1 Z1 Canada.

Tel: + 1.514.399.9132.

E-mail: chamel@ciet.org

Key words: childhood malnutrition, antenatal care, Nigeria.

Acknowledgements: authors would thank the community members who responded to questionnaires and participated in focus group discussions, as well as the fieldworkers who collected the data.

Contributions: $\mathrm{CH}$, statistical analysis and drafting of manuscript; JE, acquisition of data and statistical analysis, drafting of manuscript; KO, design, implementation of the study, drafting of manuscript; NA and YY design and revision of manuscript; $\mathrm{AC}$, design of the study, data analysis and drafting of manuscript; NA conception of study, design and coordination, revision of manuscript.

Conflict of interest: the authors declare no potential conflict of interest.

Received for publication: 14 October 2014.

Accepted for publication: 24 February 2015.

(C) Copyright C. Hamel et al., 2015

Licensee PAGEPress, Italy

Journal of Public Health Research 2015;4:408

doi:10.4081/jphr.2015.408

This work is licensed under a Creative Commons Attribution NonCommercial 3.0 License (CC BY-NC 3.0).

\section{References}

1. Ezzati M, Lopez AD, Rodgers A, et al. Selected major risk factors and global and regional burden of disease. Comparative Risk Assessment Collaborating Group. Lancet 2002;360:1347-60.

2. Black RE, Allan LH, Bhutta ZA, et al. Maternal and child undernutrition: global and regional exposures and health consequences. Lancet 2008:371:243-60.

3. World Health Organization. MDG 1: Eradicate extreme poverty and hunger. Available from: http://www.who.int/topics/ millennium_d evelopment_goals/hunger/en/index.html

4. World Health Organization. MDG 4: reduce child mortality. Available from: http://www.who.int/topics/millennium_development_goals/child_mortality/en/

5. UNICEF. Tracking Progress on Child and Maternal Nutrition. A survival and development priority. 2009. Available from: http://www.unicef.org/publications/files/Tracking_Progress_on_Ch ild_and_Maternal_Nutrition_EN_110309.pdf

6. NBS, UNICEF, UNFPA. Nigeria. Monitoring the situation of children and women. Multiple Indicator Cluster Survey 2011. Available from: www.childinfo.org/files/MICS4_Nigeria_FinalReport_2011_ Eng.pdf

7. UNICEF. The state of the World's children 1998. Focus on Nutrition. 1998. Available from: http://www.unicef.org/sowc/archive/ENGLISH/The $\% 20$ State $\% 20$ of $\% 20$ the $\% 20$ World $\% 27 s \% 20$ Children $\% 2019$ 98.pdf

8. Choudhury KK, Hanifi MA, Rasheed S, Bhuiya A. Gender inequality and severe malnutrition among children in a remote rural area of Bangladesh. J Health Popul Nutr 2000;18:123-30.

9. Hong R, Banta JE, Betancourt JA. Relationship between household wealth inequality and chronic childhood under-nutrition in Bangladesh. Int J Equity Health 2006;5:15.

10. Kikafunda JK, Walker AF, Collett D, Tumwine JK. Risk factors for early childhood malnutrition in Uganda. Pediatrics 1998;102:e45.

11. Lesiapeto MS, Smuts CM, Hanekom SM, et al. Risk factors of poor anthropometric status in children under five years of age living in rural districts of the Eastern Cape of KwaZulu-Natal provinces, South Africa. S Afr J Clin Nutr 2010;23:202-7.

12. Nahar B, Ahmed T, Brown KH, Iqbal HM. Risk Factors associated with severe underweight among young children reporting to a diarrhoea treatment facility in Bangladesh. J Health Popul Nutr 2010;28:476-83.

13. Finlay JE, Ozaltin E, Canning D. The association of maternal age with infant mortality, child anthropometric failure, diarrhoea and anaemia for first births: evidence from 55 low- and middle-income countries. BMJ Open 2011;1:e000226.

14. Yimer G. Malnutrition among children in Southern Ethiopia: levels and risk factors. Ethiop J Health Dev 2000;14:283-92.

15. Partnership for Maternal, Newborn, and Child Health. Opportunities for Africa's Newborns. Practical data, policy and programmatic support for newborn care in Africa. Available from: http://www.who.int/pmnch/media/publications/oanfullreport.pdf

16. Andersson N, Omer K, Caldwell D, et al. Male responsibility and maternal morbidity: a cross-sectional study in two Nigerian States. BMC Health Serv Res 2011;11:S7.

17. IDRC, CRDI. Nigerian evidence-based health system initiative. Available from: http://www.idrc.ca/EN/Programs/Social_and_Economic_Policy/Gov ernance_for_Equity_in_Health_Systems/Pages/nehsi.aspx

18. National Population Commission, ICF International. Nigeria. Demographic and health survey 2013. Available from: http://dhsprogram.com/pubs/pdf/FR293/FR293.pdf

19. Cross River State Government. Fact file: land and people. Available from: http://www.crossriverstate.gov.ng/index.php?option=com _content\&view=article\&id=113:land-and-people\&catid=95:factsabout-cross-river-state $\&$ Itemid $=753$

20. Morley D. Tapes for measuring mid upper arm circumference (MUAC). South Sudan Med J 2008;1.

21. Bern C, Nathanail L. Is mid-upper-arm circumference a useful tool for screening in emergency settings? Lancet 1995;345:631-3.

22. Briend A, Golden MH, Grellety Y, et al. Use of mid-upper-arm circumference for nutritional screening of refugees. Lancet 1995;345:1119-20.

23. Sandiford P, Paulin FH. Use of mid-upper-arm circumference for nutritional screening of refugees. Lancet 1995;345:1120.

24. Mei Z, Grummer-Strawn LM, de Onis M, Yip R. Development of MUAC-for-height reference, including a comparison to other nutritional status screening indicators. Bull World Health Organ 1997;75:333-41.

25. Centers of Disease Control and Prevention. EPI INFO 6 (2001). Available from: https://wwwn.cdc.gov/epiinfo/html/ ei6_downloads.htm

26. Andersson N, Mitchell S. Epidemiological geomatics in evaluation of mine risk education in Afghanistan: Introducing population weighted raster maps. Int J Health Geogr 2006;5:1.

27. World Health Organization. Child growth standards. WHO Anthro (version 3.2.2, January 2011) and macros. Available from: http://www.who.int/childgrowth/software/en/

28. Mantel N, Haenszel W. Statistical aspects of the analysis of data from retrospective studies on disease. J Natl Cancer Inst 1959;22:719-48.

29. Lamothe G. Adjusting the Mantel Haenszel test statistic and odds ratio for cluster sampling. BMC Health Serv Res 2011;11:S15.

30. Olusanya BO, Wirz SL, Renner JK. Prevalence, pattern and risk factors for under nutrition in early infancy using the WHO multicentre growth reference: a community-based study. Paediatr Perinat Epidemiol 2010;24:572-83.

31. Thousand Days. Why 1000 days. Available from: http://www.thousanddays.org/about/ 
32. Adekanmbi VT, Kayode GA, Uthman OA. Individual and contextual factors associated with childhood stunting in Nigeria: a multilevel analysis. Matern Child Nutr 2013;9:244-59.

33. Katona P, Katona-Apte J. The interaction between nutrition and infection. Clin Infect Dis 2008;46:1582-8.

34. Nel ED. Diarrhoea and malnutrition. S Afr J Clin Nutr 2010;23:S158.

35. Cashat-Cruz M, Morales-Aquirre JJ, Mendoza-Azpiri M. Respiratory tract infections in children in developing countries. Semin Pediatr Infect Dis 2005;16:84-92.
36. Rodriguez L, Cervantes E, Ortiz R. Malnutrition and gastrointestinal and respiratory infections in children: a public health problem. Int J Environ Res Public Health 2011;8:1174-205.

37. Makoka D. The impact of maternal education on child nutrition: evidence from Malawi, Tanzania, and Zimbabwe. DHS Working Papers. 2013. Available from: http://www.schoolsandhealth.org/ Shared\%20Documents/The\%20Impact\%20of\%20Maternal\%20Educ ation $\% 20$ on\%20Child\%20Nutrition\%20Evidence\%20from\%20Mala wi\%20Tanzania\%20and\%20Zimbabwe.pdf 